\title{
Tratamentos pré-germinativos e substratos na emergência de sementes e qualidade de mudas de pinhão manso (Jatropha curcas L.) ${ }^{1}$
}

\section{Pre-germinative treatments and substrate on seeds emergence and quality physic nut seedlings (Jatropha curcas L.)}

\author{
Erica Rodrigues Moreira ${ }^{2}$; Aparecida Conceição Boliani ${ }^{3}$; \\ Luiz de Souza Corrêa ${ }^{3}$; Maximiliano Kawahata Pagliarini ${ }^{4}$; \\ Danilo Marcelo Aires dos Santos ${ }^{5}$; Enes Furlani Junior ${ }^{3}$; Gustavo Alves Pereira ${ }^{6}$
}

\section{Resumo}

O pinhão manso pode ser propagado via assexuada ou sexuada. Utilizando-se estacas têm-se maior precocidade de produção e maior fidelidade das características da planta mãe. No entanto, verifica-se menor desenvolvimento vegetativo inicial. A partir de sementes as plantas tem maior variabilidade genética, são mais vigorosas ainda que iniciem a produção tardiamente. Para obter muda de qualidade, o substrato é um fator importante. Com isso objetivou-se com este trabalho avaliar tratamentos prégerminativos e substratos na emergência de sementes e na qualidade de pinhão manso. $O$ delineamento experimental utilizado foi inteiramente casualizado em esquema fatorial $6 \times 3$ (tratamentos prégerminativos $\mathrm{x}$ substratos) com 4 repetições composta por 8 sementes. Foram avaliados seis tratamentos pré-germinativos: T1: testemunha (sem tratamento); T2: imersão em água por 12 horas; T3: imersão em água por 24 horas; T4: escarificação mecânica; T5: escarificação mecânica + imersão em água por 12 horas; T6: escarificação mecânica + imersão em água por 24 horas. As sementes foram semeadas em três substratos: comercial, vermiculita média expandida e areia grossa lavada. A escarificação foi realizada no lado oposto a micrópila utilizando lixa d'água 60. Após os tratamentos pré-germinativos, as sementes foram colocadas para germinar em copos plásticos $(200 \mathrm{~mL})$ com os substratos. Avaliaramse as características: porcentagem, índice de velocidade e tempo médio de emergência, comprimento médio da planta, diâmetro de caule, índice SPAD, massa fresca e seca da parte aérea e da raiz. Os resultados obtidos permitiram concluir que em sementes de pinhão manso não há necessidade de realizar tratamentos pré-germinativos; e o uso do substrato comercial proporcionou melhor desenvolvimento das plântulas.

Palavras-chave: Biodiesel, escarificação mecânica, imersão em água, propagação sexuada

\footnotetext{
1 Parte da tese do primeiro autor

2 Dr ${ }^{\mathrm{a}}$ em Agronomia em Sistema de Produção, Universidade Estadual Paulista "Julio de Mesquita Filho", UNESP, Ilha Solteira, SP. E-mail: erica_rmoreira@hotmail.com

3 Profs., Dept ${ }^{\circ}$ de Fitotecnia, Tecnologia de Alimentos e Sócio Economia, UNESP, Ilha Solteira, SP. E-mail: boliani@agr.feis. unesp.br; 1correa@agr.feis.unesp.br; enes@agr.feis.unesp.br

4 Discente do Curso de Doutorado em Agronomia em Sistema de Produção, UNESP, Ilha Solteira, SP. E-mail: maxpagliarini@ hotmail.com

5 Pós-doutorando em Agronomia em Sistema de Produção, UNESP, Ilha Solteira, SP. E-mail: dmaires@hotmail.com

6 Pesquisador, Dr. em Agronomia em Sistema de Produção, Bolsista DCR/CNPQ, Empaer, Várzea Grande, MT. E-mail: gustavo_ apereira@yahoo.com.br

* Autor para correspondência
} 


\begin{abstract}
The physic nut can be propagated asexually or sexually. Using cuttings have been earlier yield and more fidelity characteristics of the parent plant. However, there is less initial vegetative growth. The seeds from the plants have increased genetic variability, are more vigorous and begin production later. To get quality changes, the substrate is an important factor. With that the objective was to taste pregerminated treatments and different substrate on seeds emergence and quality physic nut seedlings. The experimental design was completely randomized, in factorial scheme $6 \times 3$ (pre-germinated treatments $\mathrm{x}$ substrate), 18 treatments and 4 repetition, 8 seeds to each repetition. It was evaluated six pre-germination treatments: T1: witness (without treatments); T2: water immersion for 12 hours; T3: water immersion for 24 hours; T4: mechanical scarification; T5: mechanical scarification + water immersion for 12 hours; T6: mechanical scarification + water immersion for 24 hours, using as substrate: commercial, expanded vermiculite and sand washed. The mechanical scarification was realized opposite the micropyle using sandpaper n. 60. After the pre-germination treatments, the seeds were emergence in plastic cups $(200 \mathrm{~mL})$ with substrates. We evaluated the characteristics: percentage, beginning and emergence speed index, mean length of plant, diameter of plant stem, SPAD index, fresh and dry shoot and root. The results showed that in seeds of Jatropha do not need pre-germinative treatments; and the use of commercial substrate showed seedling development.
\end{abstract}

Key words: Biodiesel, immersion in water, mechanical scarification, sexually propagation

\section{Introdução}

O pinhão manso (Jatropha curcas L.) pertence à família das Euphorbiaceae, e provavelmente é originário das Américas Central e do Sul (HELLER, 1996). Apresenta um crescimento arbustivo, e pode chegar até quatro metros de altura (VANZOLINI et al., 2010), e suas sementes contém teor de óleo (entre 35 e $57 \%$ ), produzindo de duas a quatro toneladas de óleo por hectare por ano. Essa característica coloca o pinhão manso em uma posição promissora entre as oleaginosas utilizadas para a produção de biodiesel (CARNIELLI, 2003).

A propagação do pinhão manso pode ser feita via assexuada (vegetativa) ou via sexuada, através de sementes (SEVERINO et al., 2006), sendo que há um crescimento diferenciado das plântulas originadas vegetativamente ou via seminal. A propagação utilizando-se estacas possibilita maior precocidade de produção e reproduzem características idênticas da planta mãe. Porém, verifica-se menor crescimento vegetativo inicial. Por outro lado, plantas estabelecidas a partir de sementes apresentam maior variabilidade genética em relação à planta mãe, são mais vigorosas ainda que iniciem a produção mais tardiamente.
Quando a propagação for através de sementes, estas devem ser obtidas de plantas vigorosas, sadias e com boa produtividade (ALVES et al., 2008), e para que uma semente possa germinar são necessários suprimento de água em quantidade suficiente; temperatura e composição de gases adequados, bem como de luz para determinadas espécies (CARVALHO; NAKAGAWA, 2000). Algumas sementes não germinam mesmo quando colocadas sob condições favoráveis, sendo denominadas dormentes (CARDOSO, 2004).

Este fenômeno da dormência da semente funciona como mecanismo natural de resistência a fatores adversos do meio. A impermeabilidade do tegumento é um dos fatores que afetam a germinação, tornando-se um problema sério na medida em que impede a entrada de água e oxigênio no interior da semente, quando esta é colocada em condições adequadas para germinar, prejudicando a germinação (CARVALHO; NAKAGAWA, 2012). Para a superação da dormência em sementes um dos métodos mais utilizados é a escarificação mecânica, uma técnica prática e segura, além de ser um método simples e de baixo custo (SMIDERLE; SOUZA, 2003). 
Existem poucos relatos na literatura quanto à dormência em sementes de pinhão manso. Segundo Joker e Jepsen (2003), as sementes recém-colhidas apresentam dormência e necessitam de um período de repouso pós-colheita antes de germinar. Estudos realizados por Niranjan et al. (2010) com teste de germinação em sementes de três acessos de pinhão manso na Índia, com os tratamentos testemunha, imersão em água fria por 12 horas, imersão em água quente $\left(50{ }^{\circ} \mathrm{C}\right)$ por 15 minutos, imersão em água quente $\left(60^{\circ} \mathrm{C}\right)$ por 15 minutos, obtiveram melhor resultado quando as sementes foram imersas em água fria por 12 horas (62\%). De acordo com Sharma (2007) sementes de pinhão manso imersas em água por 12 ou 24 horas, aumentaram a taxa de germinação.

O melhor método para a propagação do pinhão manso ainda não está definido, sendo que para o sucesso de uma lavoura a qualidade da muda é um fator importante, assim como o substrato adequado a ser utilizado (COSTA; CAMARGO, 2009).

A escolha do substrato também tem fundamental importância nos resultados obtidos no teste de germinação (BRASIL, 2009). O substrato é de extrema importância para a formação da plântula, quando é utilizado propagação por sementes, devendo fornecer condições ideais para a germinação e desenvolvimento do sistema radicular da planta, ausência de patógenos, ser rico em nutrientes, $\mathrm{pH}$ adequado, boa textura e estrutura (SILVA; PEIXOTO; JUNQUEIRA, 2001).

Relatos feitos por Alves et al. (2002) e Andrade et al. (2006) demonstraram que o substrato deve manter proporção adequada entre a disponibilidade de água e aeração e não deve ser umedecido em excesso, para evitar que a película de água envolva completamente a semente e diminua a entrada e absorção de oxigênio. Segundo Diniz, Guimarães e Luz (2006) e Oliveira et al. (2008) a vermiculita é normalmente um bom agente na melhoria das condições físicas do solo e, ainda apresenta-se quimicamente ativa, liberando íons magnésio para a solução do solo e absorvendo fósforo e nitrogênio na forma amoniacal.

Diante do exposto objetivou-se com este trabalho avaliar tratamentos pré-germinativos e substratos na germinação de sementes e na qualidade de mudas de pinhão manso.

\section{Material e Métodos}

O experimento foi realizado na Faculdade de Engenharia da Universidade Estadual Paulista (UNESP), Campus de Ilha Solteira, localizado a $20^{\circ} 25^{\prime} 28^{\prime \prime}$ de latitude sul e $51^{\circ} 21^{\prime} 15^{\prime \prime}$ de longitude oeste, com altitude em torno de $354 \mathrm{~m}$, em casa de vegetação tipo Pad \& Fan (sistema de resfriamento e umidificação), com temperatura média de $25^{\circ} \mathrm{C}$ e umidade relativa de $60 \%$, no período de 20 de agosto a 20 de setembro de 2011 .

As sementes utilizadas não passaram por tratamentos fitossanitários e foram provenientes de plantas matrizes com dois anos de idade, que foram propagadas por estaquia, na Fazenda de Ensino, Pesquisa e Extensão da Faculdade de Engenharia da UNESP de Ilha Solteira, localizada em Selvíria MS, onde foram colhidas em 14 de Abril de 2011 e mantidas em câmara fria em temperatura de $4{ }^{\circ} \mathrm{C}$ e umidade relativa de $21 \%$.

O delineamento experimental utilizado foi inteiramente casualizado, em esquema fatorial 6 x 3 (tratamentos pré-germinativos x substratos) totalizando 18 tratamentos com 4 repetições, sendo que cada unidade experimental foi composta por 8 sementes. Os tratamentos pré-germinativos utilizados foram: T1: Testemunha - sem tratamento pré-germinativo; T2: imersão em água por 12 horas; T3: imersão em água por 24 horas; T4: escarificação mecânica; T5: escarificação mecânica + imersão em água por 12 horas; T6: escarificação mecânica + imersão em água por 24 horas. Foram utilizados três substratos: comercial Bioplant ${ }^{\circledR}$ composto de: casca de Pinus, fibra de coco, vermiculita, agentes agregantes, NPK e micronutrientes, com alta 
capacidade de troca catiônica (CTC) e capacidade de retenção de água; vermiculita de textura média e areia grossa lavada. A escarificação mecânica foi realizada no lado oposto a micrópila, atritando-se levemente a semente em lixa d'água 60.

Após a realização dos tratamentos prégerminativos, as sementes foram colocadas para germinar em copos plásticos com capacidade de 200 $\mathrm{mL}$, com os substratos. $\mathrm{O}$ experimento foi irrigado diariamente por aspersão automática, durante três minutos as 6,12 e 18 horas.

As características avaliadas foram: emergências $(\% \mathrm{E})$, obtida através da contagem do número de sementes germinadas quando houve a emissão do hipocótilo; índice de velocidade de emergência (IVE) determinado a partir da contagem diária do número de plântulas normais identificadas durante a emergência, utilizando a formula citada por Maguire (1962); tempo médio de germinação (TMG), determinado mediante a contagem diária do número de plântulas normais identificadas no teste de germinação durante 30 dias, segundo a equação proposta por Edmond e Drapala (1958); altura das plântulas $(\mathrm{cm})$, medida entre a região do colo e a gema apical, com auxilio de régua graduada em centímetros; diâmetro médio do caule das plantas (cm), medido na altura do colo das plântulas com o auxílio de um paquímetro digital com precisão de 0,01mm; Soil Plant Analysis Development (Índice SPAD): medido com auxílio de clorofilômetro, cujas leituras foram tomadas em duas folhas, uma no ápice e outra na parte mediana de cada planta, obtendo-se valores médios; massa fresca e seca da parte aérea e das raízes $(\mathrm{g})$, onde a parte aérea foi separada das raízes e cada parte foi pesada individualmente, com auxilio de uma balança digital. Em seguida, foram colocadas em sacos de papel devidamente identificados, e colocados em estufa a $65^{\circ} \mathrm{C}$ por 72 horas, até atingir a massa constante, pesando-se novamente para obter a massa seca.

Os dados de porcentagem de germinação foram transformados em arc sen raiz quadrada de (x / 100), e os de massa fresca da parte aérea e da raiz, massa seca da parte aérea e da raiz em raiz quadrada de $(\mathrm{x}+0,5)$, para a normalização de sua distribuição (BARTLETT, 1947). Os dados coletados foram submetidos à análise de variância e as médias foram comparadas pelo teste de Tukey ao nível de 5\% de significância, utilizando-se o programa SANEST.

\section{Resultados e Discussão}

ATabela 1 contém os quadrados médios e os níveis de significância para as características avaliadas. Houve interação entre os fatores (tratamentos prégerminativos e substratos) para a porcentagem de emergência $(\% \mathrm{E})$, índice de velocidade de emergência (IVE) e tempo médio de emergência (TME). Analisando os fatores isoladamente para as variáveis que não apresentaram significância na interação, observou-se para o fator tratamentos prégerminativos, que houve resultados significativos para o índice SPAD; e para o fator substrato para altura de plantas (AP), diâmetro de caule (DC) e índice SPAD.

Em relação à porcentagem de emergência (Tabela 2), todos os tratamentos proporcionaram a emergência das sementes. Analisando-se cada tratamento pré-germinativo nos diversos substratos pode-se observar que o tratamento que teve maior emergência, 98\%, foi escarificação e imersão em água por 12 horas e o substrato vermiculita, não diferindo dos demais tratamentos. O mesmo não ocorreu quando as sementes emergiram em substrato comercial e areia, pois a maior porcentagem de emergência ocorreu quando não se realizou tratamento pré-germinativo, com $91 \%$ e $86 \%$, de emergência, respectivamente. As sementes de pinhão manso emergiram, mesmo quando o tegumento não foi rompido e imerso em água, concordando com Crepaldi, Santana e Lima (1998). Os mesmos autores relataram que a primeira fase da germinação é a embebição, que consiste na absorção de água pelas sementes, ocorrendo aumento de volume e massa das sementes e consequentemente 
o início dos processos fisiológicos. Smiderle, Lima e Paulino (2013) verificaram que as sementes de pinhão manso apresentaram as três fases fisiológicas semelhantes nas sementes com tamanhos pequenos e grandes, iniciando a fase II após 32 horas de embebição estendendo até 116 horas, quando inicia a fase III.

Tabela 1. Quadrados médios e níveis de significância das características avaliadas de sementes de pinhão manso (Jatropha curcas L.) submetidas a tratamentos pré-germinativos em três substratos. Ilha Solteira - SP, 2011.

\begin{tabular}{lcccccc}
\hline \multicolumn{7}{c}{ Quadrado Médio } \\
\hline \multirow{2}{*}{ Causa de variação } & E & IVE & TME & AP & DC & Índice \\
& $(\%)$ & & $($ dias $)$ & $(\mathrm{cm})$ & $(\mathrm{mm})$ & \begin{tabular}{c} 
SPAD \\
\hline Tratamentos (T)
\end{tabular} \\
Substratos (S) & $798,53^{* *}$ & $0,15^{*}$ & $1,03^{* *}$ & $3,40^{\text {ns }}$ & $0,50^{\text {ns }}$ & $59,61^{*}$ \\
T x S & $2669,99^{* *}$ & $0,43^{* *}$ & $2,12^{* *}$ & $395,38^{* *}$ & $28,57^{* *}$ & $390,97^{* *}$ \\
\hline C.V. $(\%)$ & $5426,96^{*}$ & $0,20^{* *}$ & $0,77^{* *}$ & $4,46^{\text {ns }}$ & $1,14^{\text {ns }}$ & $37,76^{\text {ns }}$ \\
\hline
\end{tabular}

** $(\mathrm{p}<0,01) ; *(\mathrm{p}<0,05) ;{ }^{\text {ns }}$ (Não significativo); C.V.= coeficiente de variação.

$\% \mathrm{E}=$ porcentagem de emergência, IVE $=$ índice de velocidade de emergência, $\mathrm{TME}=$ tempo médio de emergência, $\mathrm{AP}=$ altura da plântula, DC = diâmetro de caule.

Fonte: Elaboração dos autores.

Alguns trabalhos apresentaram resultados diferentes dos encontrados no presente trabalho como no de Mendes etal. (2009), onde os tratamentos pré-germinativos contribuíram para aumentar a porcentagem de germinação das sementes de mamona, sendo que escarificação com lixa e a remoção da carúncula ou do tegumento foram os mais eficientes sem imersão em água. Niranjan et al. (2010) em três acessos de pinhão manso verificaram que sementes imersas em água fria por 12 horas apresentaram o melhor resultado (62\%) em relação às sementes sem tratamento (51\%), imersão em água a $50{ }^{\circ} \mathrm{C}$ e $60{ }^{\circ} \mathrm{C}$ durante 15 minutos $(44 \%$ nas duas temperaturas).

Com relação aos substratos, Alves et al. (2002) e Andrade et al. (2006) relataram que o substrato deve manter proporção adequada entre a disponibilidade de água e aeração e não deve ser umedecido em excesso, para evitar que a película de água envolva completamente a semente e diminua a entrada e absorção de oxigênio; e segundo Diniz, Guimarães e Luz (2006) e Oliveira et al. (2008) a vermiculita é normalmente um bom agente na melhoria das condições físicas do solo e, ainda é quimicamente ativa, liberando íons magnésio para a solução do solo e absorve fósforo e nitrogênio na forma amoniacal.

Na Tabela 3, onde constam os dados de IVE, observa-se para o desdobramento da interação entre tratamentos pré-germinativos e substratos que, a escarificação + imersão em água por 12 horas (T5) e o substrato vermiculita, teve maior valor de IVE $(1,17)$, e a escarificação + imersão em água por 24 horas (T6) proporcionou IVE de 0,97. O substrato comercial sem tratamento pré-germinativo $(1,09)$ diferiu estatisticamente do tratamento escarificação + imersão em água por 24 horas $(0,30)$, enquanto para areia, não houve diferença estatística entre os tratamentos, obtendo maior valor de IVE, 0,97, quando não se utilizou tratamento pré-germinativo (testemunha).

Em trabalhos realizados por Silva et al. (2008) com sementes de pinhão manso, foram encontrados valores de IVE de 1,86 para sementes com tegumento, semeadas em areia, e para sementes sem tegumento o IVE foi de 1,06, valores superiores ao encontrado no presente trabalho quando se utilizou a areia como substrato. Da mesma forma, Melo et al. (2011) também verificaram que escarificação 
mecânica com lixa mais imersão em água por oito horas ocasionou maior IVE em sementes de faveira (Parkia panurensis).

Para tempo médio de emergência (TME), consta na Tabela 4 o desdobramento para a interação entre tratamentos pré-germinativos e substratos. Os substratos comercial e areia, não tiveram diferenças estatísticas entre os tratamentos. Para a vermiculita, a testemunha diferiu dos demais tratamentos, apresentando maior TME $(8,5)$.

Estudos realizados por Silva et al. (2009), com emergência de plântulas de pinhão manso utilizando como substrato areia lavada em canteiro, observaram que não houve diferença significativa para os tratamentos estudados com relação ao TME ao final de 21 dias, sendo que no tratamento: rafe para baixo, a germinação ocorreu com 16,96 dias, enquanto o tratamento carúncula para baixo o TMG foi de 16,24 dias, valores esses superiores ao encontrado neste trabalho.

Analisando conjuntamente as Tabelas 2, 3 e 4, nota-se que os substratos com maiores porcentagens de emergência (vermiculita e comercial), proporcionaram maiores IVE, e o substrato comercial menor TME. Isso significa que quando se utiliza substrato comercial e o tratamento escarificação + imersão em água por 12 horas $(6,17)$, às sementes precisaram de menos dias para iniciar 0 processo de emergência. Desta forma, as plântulas cultivadas em substrato comercial podem se tornar menos vulneráveis às condições adversas do meio, por emergirem mais rápido e passarem menos tempo nos estádios iniciais de desenvolvimento.

Tabela 2. Porcentagem de emergência de sementes de pinhão manso (Jatropha curcas L.) submetidas a tratamentos pré-germinativos em três substratos. Ilha Solteira - SP, 2011.

\begin{tabular}{lccc}
\hline & \multicolumn{3}{c}{ Emergência (\%) } \\
\hline \multirow{2}{*}{ Tratamentos Pré-Germinativos } & Comercial & Areia & Vermiculita \\
\cline { 2 - 4 } & $91 \mathrm{aA}$ & $86 \mathrm{aA}$ & $93 \mathrm{aA}$ \\
\hline Testemunha (sem tratamento) & $80 \mathrm{aA}$ & $44 \mathrm{aA}$ & $78 \mathrm{aA}$ \\
Água (12h) & $60 \mathrm{abB}$ & $47 \mathrm{aB}$ & $95 \mathrm{aA}$ \\
Água (24h) & $80 \mathrm{aA}$ & $77 \mathrm{aA}$ & $69 \mathrm{aA}$ \\
Escarificação & $53 \mathrm{abB}$ & $39 \mathrm{aB}$ & $97 \mathrm{aA}$ \\
Escarificação + Água (12h) & $24 \mathrm{bB}$ & $47 \mathrm{aB}$ & $86 \mathrm{aA}$ \\
Escarificação + Água (24h) &
\end{tabular}

Médias seguidas de letras distintas minúscula na coluna e maiúscula na linha diferem entre si pelo teste de Tukey a $5 \%$ de probabilidade.

Fonte: Elaboração dos autores.

Em relação à altura da plântula, quando se utilizou o substrato comercial, as plantas obtiveram maior altura $(12,17 \mathrm{~cm})$, diferindo dos demais tratamentos. O menor tamanho de plântula $(4,45$ $\mathrm{cm}$ ) ocorreu com o uso da vermiculita (Tabela 5).

A maior altura da plântula com uso do substrato comercial pode ter ocorrido pelo fato deste substrato conter em sua composição elementos que proporcionam o crescimento de plântulas como: casca de pinus e eucalipto, fibra e pó de coco, serragem de madeira, esterco, vermiculita, e adubos como superfosfato simples, carbonato de cálcio e magnésio, superfosfato de cálcio, entre outros. Estes resultados diferem dos encontrados por Medeiros et al. (2010) e Camargo et al. (2011), que encontraram maiores alturas de plântulas de pinhão manso, 23,17 $\mathrm{cm}$, aos 90 dias quando utilizaram como substrato solo com diferentes porcentagens de esterco bovino (até 60\%). 
Tabela 3. Índice de velocidade de emergência (IVE) de sementes de pinhão manso (Jatropha curcas L.) submetidas a tratamentos pré-germinativos em três substratos. Ilha Solteira - SP, 2011.

\begin{tabular}{|c|c|c|c|}
\hline \multirow{3}{*}{ Tratamentos Pré-Germinativos } & \multicolumn{3}{|c|}{ Índice de Velocidade de Emergência } \\
\hline & \multicolumn{3}{|c|}{ Substratos } \\
\hline & Comercial & Areia & Vermiculita \\
\hline Testemunha (sem tratamento) & $1,09 \mathrm{aA}$ & $0,97 \mathrm{aA}$ & $0,84 \mathrm{aA}$ \\
\hline Água (12h) & $0,93 \mathrm{aA}$ & $0,54 \mathrm{aB}$ & $0,81 \mathrm{aAB}$ \\
\hline Água (24h) & $0,68 \mathrm{abAB}$ & $0,56 \mathrm{aB}$ & $1,07 \mathrm{aA}$ \\
\hline Escarificação & $0,88 \mathrm{aA}$ & $0,90 \mathrm{aA}$ & $0,76 \mathrm{aA}$ \\
\hline Escarificação + Água (12h) & $0,69 \mathrm{abB}$ & $0,50 \mathrm{aB}$ & $1,17 \mathrm{aA}$ \\
\hline Escarificação + Água (24h) & $0,30 \mathrm{bB}$ & $0,57 \mathrm{aB}$ & $0,97 \mathrm{aA}$ \\
\hline
\end{tabular}

Médias seguidas de mesma letra minúscula na coluna e maiúscula na linha não diferem entre si pelo teste de Tukey a 5\% de probabilidade

Fonte: Elaboração dos autores.

Tabela 4. Tempo médio de emergência (TME, dias) de sementes de pinhão manso (Jatropha curcas L.) submetidas a tratamentos pré-germinativos em três substratos. Ilha Solteira - SP, 2011.

\begin{tabular}{lccc}
\hline & \multicolumn{3}{c}{ Tempo Médio de Emergência (dias) } \\
\hline \multirow{2}{*}{ Tratamentos Pré-Germinativos } & Comercial & Areia & Vermiculita \\
\cline { 2 - 4 } & $6,35 \mathrm{aB}$ & $6,90 \mathrm{aB}$ & $8,50 \mathrm{aA}$ \\
\hline Testemunha (sem tratamento) & $6,65 \mathrm{aA}$ & $6,61 \mathrm{aA}$ & $7,16 \mathrm{bA}$ \\
Água (12h) & $7,15 \mathrm{aA}$ & $6,73 \mathrm{aA}$ & $6,95 \mathrm{bA}$ \\
Água (24h) & $7,05 \mathrm{aA}$ & $6,91 \mathrm{aA}$ & $7,35 \mathrm{baA}$ \\
Escarificação & $6,17 \mathrm{aA}$ & $6,62 \mathrm{aA}$ & $6,50 \mathrm{bA}$ \\
Escarificação + Água $(12 \mathrm{~h})$ & $6,58 \mathrm{aA}$ & $6,70 \mathrm{aA}$ & $6,81 \mathrm{bA}$ \\
Escarificação + Água $(24 \mathrm{~h})$ &
\end{tabular}

Médias seguidas de letras distintas minúscula na coluna e maiúscula na linha diferem entre si pelo teste de Tukey a $5 \%$ de probabilidade.

Fonte: Elaboração dos autores.

Tabela 5. Valores médios de altura, diâmetro do caule e índice SPAD de plântulas de pinhão manso (Jatropha curcas L.). Ilha Solteira - SP, 2011.

\begin{tabular}{lccc}
\hline & $\begin{array}{c}\text { Altura da Plântula } \\
(\mathrm{cm})\end{array}$ & $\begin{array}{c}\text { Diâmetro do Caule } \\
(\mathrm{mm})\end{array}$ & Índice SPAD \\
\hline Substratos & & & \\
\hline Comercial & $12,17 \mathrm{a}$ & $7,49 \mathrm{a}$ & $16,78 \mathrm{c}$ \\
Areia & $10,48 \mathrm{~b}$ & $6,65 \mathrm{~b}$ & $20,27 \mathrm{~b}$ \\
Vermiculita & $4,45 \mathrm{c}$ & $5,32 \mathrm{c}$ & $24,83 \mathrm{a}$ \\
\hline Tratamentos & & & \\
\hline Testemunha (sem tratamento) & $9,80 \mathrm{a}$ & $6,70 \mathrm{a}$ & $21,26 \mathrm{ab}$ \\
Água (12h) & $9,37 \mathrm{a}$ & $6,25 \mathrm{a}$ & $21,91 \mathrm{ab}$ \\
Água (24h) & $8,51 \mathrm{a}$ & $6,72 \mathrm{a}$ & $18,11 \mathrm{~b}$ \\
Escarificação & $8,66 \mathrm{a}$ & $6,38 \mathrm{a}$ & $23,98 \mathrm{a}$ \\
Escarificação + Água (12h) & $9,30 \mathrm{a}$ & $6,57 \mathrm{a}$ & $20,09 \mathrm{ab}$ \\
Escarificação + Água (24h) & $8,55 \mathrm{a}$ & $6,29 \mathrm{a}$ & $18,41 \mathrm{~b}$ \\
\hline
\end{tabular}

Médias seguidas de letras distintas na coluna diferem entre si pelo teste de Tukey a 5\% de probabilidade.

Fonte: Elaboração dos autores. 
A maior altura da plântula com uso do substrato comercial pode ter ocorrido pelo fato deste substrato conter em sua composição elementos que proporcionam o crescimento de plântulas como: casca de pinus e eucalipto, fibra e pó de coco, serragem de madeira, esterco, vermiculita, e adubos como superfosfato simples, carbonato de cálcio e magnésio, superfosfato de cálcio, entre outros. Estes resultados diferem dos encontrados por Medeiros et al. (2010) e Camargo et al. (2011), que encontraram maiores alturas de plântulas de pinhão manso, 23,17 $\mathrm{cm}$, aos 90 dias quando utilizaram como substrato solo com diferentes porcentagens de esterco bovino (até 60\%).

Para diâmetro do caule, o maior valor foi obtido com substrato comercial $(7,49 \mathrm{~mm})$, seguido da areia $(6,65 \mathrm{~mm})$ e da vermiculita $(5,32 \mathrm{~mm})$ (Tabela $5)$. Estes resultados discordam daqueles encontrados por Dourado (2009), que estudando diferentes genótipos de pinhão manso, cultivados em vasilhas tipo marmitex com 1/3 de solo e 2/3 de areia, obteve maior diâmetro, $5,7 \mathrm{~cm}$, para o genótipo Paraguaçu, 36 dias após a semeadura.

Estudos realizados por Lima et al. (2011) com diferentes substratos para formação de mudas em condições de casa de vegetação, permitiram concluir que a mistura de composto de lixo + lodo de esgoto + terra, na proporção de $1: 1: 1$, proporciona maior diâmetro $(11,47 \mathrm{~cm})$. Já Camargo et al. (2011) estudando fontes e concentrações de matéria orgânica para produção de mudas de pinhão manso, aos 90 dias após a emergência, não observaram diferenças significativa para a variável diâmetro do caule, com relação a fonte de matéria orgânica, obtendo $9,97 \mathrm{~cm}$ quando utilizou-se esterco bovino e $8,50 \mathrm{~cm}$ para cama de frango.

Comparando as características altura e diâmetro da plântula, observou-se que o substrato comercial, proporcionou maior altura corresponde ao substrato com plântulas de maior diâmetro de caule; Esse fato pode evitar o tombamento das plântulas, já que possivelmente, que o menor diâmetro pode interferir em estrutura de sustentação pouco adequada ao seu porte. De acordo com Daniel et al. (1997) e Carneiro (1995) a característica diâmetro de caule é a mais indicada para inferir sobre a capacidade de sobrevivência da muda no campo.

Para o índice SPAD (Tabela 5) o substrato vermiculita proporcionou maior valor $(24,83)$, diferindo significativamente dos demais. Com relação aos tratamentos utilizados, a escarificação teveíndice SPAD de 23,98, diferindo dos tratamentos imersão em água $(24 \mathrm{~h})(18,11)$ e escarificação + imersão em água (24h) $(18,41)$. Segundo Zotarelli et al. (2002) o medidor de clorofila SPAD-502 detecta a quantidade de cor verde na folha através da quantidade de luz de comprimento de onda da região vermelho e infravermelho. A quantidade de luz vermelha absorvida indica a quantidade de clorofila, enquanto que a quantidade de luz absorvida próximo ao infravermelho serve como uma referência interna na compensação da espessura da folha e conteúdo de água.

Em estudos realizados em plantas de pinhão manso por Cavalcante et al. (2009), em condições de solo salinizados, as folhas apresentaram unidade SPAD de 39,6. Entretanto, Santos (2008) observou valores médios de 41,52 e 42,68 de leituras SPAD em folhas de pinhão manso, superiores ao encontrado neste trabalho com uso de substratos. O índice SPAD em substrato comercial foi significativamente inferior aos demais.

Os quadrados médios e os níveis de significância das variáveis: massa fresca e seca da parte aérea, massa fresca e seca das raízes estão descritos na Tabela 6. As variáveis massa fresca e seca das raízes apresentaram resultados significativos para os tratamentos pré-germinativos. Houve resultados significativos para todas as variáveis analisadas, no fator substrato, e para a interação não houve significância. Com relação ao fator substrato, o comercial diferiu significativamente dos demais substratos, proporcionando maiores valores para massa fresca $(9,18 \mathrm{~g})$ e massa seca $(7,91 \mathrm{~g})$ da parte aérea; e massa fresca $(1,37 \mathrm{~g})$ e massa seca das raízes $(1,17 \mathrm{~g})$ (Tabela 7$)$. 
Tabela 6. Quadrados médios e níveis de significância das características avaliadas de plântulas de pinhão manso (Jatropha curcas L.) submetidas a diferentes tratamentos pré-germinativos em três substratos. Ilha Solteira - SP, 2011.

\begin{tabular}{lcccc}
\hline \multicolumn{4}{c}{ Quadrado Médio } \\
\hline \multirow{2}{*}{ Causa de variação } & MFPA & MSPA & MFR & MSR \\
\cline { 2 - 5 } & \multicolumn{3}{c}{$(\mathrm{g})$} \\
\hline Tratamentos & $0,2^{\text {ns }}$ & $0,17^{\text {ns }}$ & $0,1^{* *}$ & $0,075^{*}$ \\
Substrato & $11,56^{* *}$ & $10,31^{* *}$ & $0,9^{* *}$ & $0,68^{* *}$ \\
Tratamentos x Substrato & $0,1^{\text {ns }}$ & $0,09^{\text {ns }}$ & $0,027^{\text {ns }}$ & $0,028^{\text {ns }}$ \\
\hline C.V. $(\%)$ & 18,31 & 18,35 & 14,16 & 14,61 \\
\hline
\end{tabular}

** $(\mathrm{p}<0,01) ; *(\mathrm{p}<0,05) ;{ }^{\text {ns }}$ (Não significativo); C.V.= coeficiente de variação.

MFPA= massa fresca da parte aérea, MSPA = massa seca da parte aérea, MFR = massa fresca da raiz, MSR = massa seca raiz.

Fonte: Elaboração dos autores.

Tabela 7. Valores médios em gramas para massa fresca da parte aérea (MFPA), massa seca da parte aérea (MSPA), massa fresca da raiz (MFR) e massa seca da raiz (MSR) de plântulas de pinhão manso (Jatropha curcas L.) submetidas a diferentes tratamentos pré-germinativos em três substratos. Ilha Solteira - SP, 2011.

\begin{tabular}{lcccc}
\hline \multirow{2}{*}{ Substratos } & MFPA & MSPA & MFR & MSR \\
\cline { 2 - 5 } & \multicolumn{2}{c}{$(\mathrm{g})$} & $1,37 \mathrm{a}$ & $1,17 \mathrm{a}$ \\
Comercial & $9,18 \mathrm{a}$ & $7,91 \mathrm{a}$ & $0,94 \mathrm{~b}$ & $0,66 \mathrm{~b}$ \\
Areia & $5,94 \mathrm{~b}$ & $4,93 \mathrm{~b}$ & $0,46 \mathrm{c}$ & $0,42 \mathrm{c}$ \\
Vermiculita & $2,49 \mathrm{c}$ & $1,59 \mathrm{c}$ & & \\
\hline Tratamentos & & & $1,24 \mathrm{a}$ & $1,00 \mathrm{a}$ \\
\hline Testemunha & $2,54^{\mathrm{a}}$ & $2,34 \mathrm{a}$ & $1,09 \mathrm{ab}$ & $0,89 \mathrm{ab}$ \\
Água (12h) & $2,60^{\mathrm{a}}$ & $2,42 \mathrm{a}$ & $0,84 \mathrm{ab}$ & $0,68 \mathrm{ab}$ \\
Água (24h) & $2,37^{\mathrm{a}}$ & $2,20 \mathrm{a}$ & $0,77 \mathrm{ab}$ & $0,61 \mathrm{ab}$ \\
Escarificação & $2,26^{\mathrm{a}}$ & $2,08 \mathrm{a}$ & $0,85 \mathrm{ab}$ & $0,70 \mathrm{ab}$ \\
Escarificação + Água (12h) & $2,54^{\mathrm{a}}$ & $2,34 \mathrm{a}$ & $0,64 \mathrm{~b}$ & $0,53 \mathrm{~b}$ \\
Escarificação + Água (24h) & $2,42^{\mathrm{a}}$ & $2,24 \mathrm{a}$ & &
\end{tabular}

Médias seguidas de letras distintas diferem entre si pelo teste de Tukey a 5\% de probabilidade.

Fonte: Elaboração dos autores.

Para os tratamentos pré-germinativos nas características massa fresca e seca da raiz, a testemunha (T1) proporcionou maiores valores, $1,24 \mathrm{~g}$ e $1,0 \mathrm{~g}$, respectivamente, diferindo apenas da escarificação + imersão em água por 24 horas (T6) que obteve 0,64 g para massa fresca de raízes e 0,53 g para massa seca de raízes.

Com relação à produção de biomassa da parte aérea, Camargo et al. (2010) observaram na ausência do tratamento de semente, o maior acúmulo de massa seca, e para a variável massa seca de raízes não foi encontrada diferença significativa para $o$ fator tratamento de sementes. Assim como, Silva et al. (2009) também não observaram diferença estatística para massa seca da parte área e das raízes de pinhão manso em função da posição da semente utilizando como substrato a areia. Estudos realizados com compostos para produção de mudas de pinhão manso verificaram que a combinação de composto de lixo + torta de mamona + terra, na proporção de 1:1:1 (v/v/v) proporcionou valores de 9,55 e 2,02 para massa fresca da parte aérea e seca das raízes, respectivamente (LIMA et al., 2011).

No presente trabalho, os maiores valores quanto à massa fresca e seca de raízes foram encontrados com a utilização do substrato comercial. Provavelmente esses resultados ocorreram devido à areia e a vermiculita serem materiais inertes, enquanto o substrato comercial apresenta em sua composição NPK e micronutrientes. 


\section{Conclusões}

Em sementes de pinhão manso não há necessidade de se realizar tratamento pré-germinativo, porém a utilização da escarificação + imersão em água por 12 horas proporcionou maiores porcentagens de emergência na vermiculita.

O substrato comercial melhorou a qualidade das mudas apresentando maiores valores para altura, diâmetro, massa fresca e seca das partes aéreas e das raízes.

\section{Agradecimentos}

Á Fundunesp/ Petrobrás pela concessão da bolsa.

\section{Referências}

ALVES, E. U.; PAUlA, R. C.; OLIVEIRA, A. P.; BRUNO, R. L. A.; DINIZ, A. A. Germinação de sementes de Mimosa caesalpiniae folia Benth. em diferentes substratos e temperaturas. Revista Brasileira de Sementes, Londrina, v. 24, n. 1, p. 169-178, 2002.

ALVES, J. M. A.; SOUZA, A. de A.; SILVA, S. R. G. da; LOPES, G. N.; SMIDERLEO, J.; UCHOA, S. C. P. Pinhão-Manso: Uma Alternativa para Produção de Biodiesel na Agricultura Familiar da Amazônia Brasileira.Agro@mbiente, Boa Vista, v. 2, n. 1, p. 57-68, 2008.

ANDRADE, A. C. S.; PEREIRA, T. S.; FERNANDES, M. J.; CRUZ, A. P. M.; CARVALHO, A. S. R. Substrato, temperatura de germinação e desenvolvimento pósseminal de sementes de Dalbergia nigra. Pesquisa Agropecuária Brasileira, Brasília, v. 41, n. 3, p. 517-523, 2006.

BARTLETT, M. S. The use of transformations. Biometrics, Washington, v. 3, n. 4, p. 39-52, 1947.

BRASIL. Ministério da Agricultura, Pecuária e Abastecimento. Regras para análise de sementes. Ministério da Agricultura, Pecuária e Abastecimento. Secretaria de Defesa Agropecuária. Brasília: MAPA/ ACS, 2009. 395 p.

CAMARGO, R.; MALDONADO, A. C. D.; SILVA, P. A.; COSTA, T. R. Biossólido como substrato na produção de mudas de pinhão-manso. Revista Brasileira de Engenharia Agrícola e Ambiental, Campina Grande, v. 14, n. 12, p. 1304-1310, 2010.
CAMARGO, R.; PIRES, S. C.; MALDONADO, A. C. D.; CARVAlHO, H. P.; COSTA, T. R. Avaliação de substratos para a produção de mudas de pinhão-manso em sacolas plásticas. Revista Trópica - Ciências Agrárias e Biológicas, Uberlândia, v. 5, n. 1, p. 31-38, 2011.

CARDOSO, V. J. M. Dormência: estabelecimento do processo. In: FERREIRA, A. G.; BORGHETTI, F. Germinação: do básico ao aplicado. Porto Alegre: Artmed, 2004. p. 95-108.

CARNEIRO, J. G. A. Produção e controle da qualidade de mudas florestais. Curitiba: UFPR/FUPEF, 1995. 451 p.

CARNIELLI, F. O combustivel do futuro. Belo Horizonte: Universidade Federal de Minas Gerais- UFMG, 2003. (Boletim Técnico). Disponível em: <http://www.ufmg. br/boletim/bul1413 >. Acesso em: 1 abr. 2012.

CARVALHO, N. M.; NAKAGAWA, J. Sementes: ciência, tecnologia e produção. 4. ed. Jaboticabal: FUNEP, 2000. 588 p.

. Sementes: ciência, tecnologia e produção. 5. ed. Jaboticabal: FUNEP, 2012. 590 p.

CAVALCANTE, P. G. S.; WANDERLEY FILHO, H. C. L.; GONÇALVES, E. R.; VERISSIMO, V.; SILVA, I. M.; DUARTE, W. G.; PEREIRA, F. M. Avaliação do teor de clorofila em pinhão-manso (Jatropha curcas L.) sob estresse salino. In: CONGRESSO BRASILEIRO DE FISIOLOGIA VEGETAL 12., 2009, Fortaleza. Anais... Fortaleza: SBFV: UFC, 2009. 1 CD-ROM.

COSTA, T. R.; CAMARGO, R. Produção de mudas de pinhão manso (Jatropha curcas L.) em tubetes a partir de diferentes fontes de matéria orgânica. Revista Horizonte Científico, Uberlândia, v. 3, n. 1, p. 1-16, 2009.

CREPALDI, I. C.; SANTANA, J. R. F. de; LIMA, P. B. Quebra de dormência de pau-ferro (Caesalpinia férrea Mart. exTul. - Leguminosae, Caesalpinioideae). Sitientibus, Feira de Santana, v. 5, n. 18, p. 19-29, 1998.

DANIEL, O.; VITORINO, A. C. T.; ALOVISI, A. A.; MAZZOCHIN, L.; TOKURA, A. M.; PINHEIRO, E. R. SOUZA, E. F. Aplicação de fósforo em mudas de Acacia mangium Willd. Revista Árvore, Viçosa, v. 21, n. 2, p. 163-168, 1997.

DINIZ, K. A.; GUIMARÃES, S. T. M. R.; LUZ, J. M. Q. Húmus como substrato para a produção de mudas de tomate, pimentão e alface. Bioscience Journal, Uberlândia, v. 22, n. 3, p. 63-70, 2006.

DOURADO, F. N. Avaliação da qualidade de sementes e plântulas de pinhão manso (Jatropha curcas L.) 2009. Dissertação (Mestrado em Fitotecnia) - Faculdade de Ciências Agrárias, Universidade Estadual do Sudoeste da Bahia, Vitória da Conquista. 
EDMOND, J. B.; DRAPALA, W. J. The effects of temperature, sand and soil, and acetone on germination of okra seed. Proceeding of American Society for Horticultural Science, Geneva, v. 71, n. 1, p. 428-434, 1958.

HELLER, J. Physic nut. Jatropha curcas L. Promoting the conservation and use of underutilized and neglected crops. Rome: Institute of Plant Genetics and Crop Plant Research, Gatersleben/ International Plant Genetic Resources Institute, 1996. 66 p.

JOKER, D.; JEPSEN, J. Jatropha curcas L. Humleback: Seed Leaflet, 2003. n. 83, p. 1- 2.

LIMA, R. L. S.; SEVERINO, L. S.; FERREIRA, G. B.; SOFIATTIS, V.; SAMPAIO, L. R.; BELTRÃO, N. E. M. Casca de mamona associada a quatro fontes de matéria orgânica para a produção de mudas de pinhão-manso. Revista Ceres, Viçosa, v. 58, n. 2, p. 232-237, 2011.

MAGUIRE, J. D. Speed of germination aid in selection and evaluation for seedling emergence and vigor. Crop Science, Madison, v. 2, n. 2, p. 176-177, 1962.

MEDEIROS, K. A. A. L.; SOFIATTI, V.; SILVA, H.; LIMA, R.; LUCENA, A. M. A.; VASCONCELOS, G. C.; ARRIEL, N. H. C. Mudas de pinhão manso (Jatropha curcas L.) produzidas em diferentes fontes e doses de matéria orgânica. In: CONGRESSO BRASILEIRO DE MAMONA; SIMPÓSIO INTERNACIONAL DE OLEAGINOSAS ENERGÉTICAS, 4, 1., 2010, João Pessoa. Anais... Campina Grande: Embrapa Algodão, 2010. p. 1413-1419.

MELO, M. das G. G.; MENDONÇA, M. S. de; NAZÁRIO, P.; MENDES, A. M. da S. Superação de dormência em sementes de três espécies de Parkia spp. Revista Brasileira de Sementes, Londrina, v. 33, n. 3, p. 533-542, 2011.

MENDES, R. de C.; DIAS, D. C. F. S.; PEREIRA, M. C.; BERGER, P. G. Tratamentos pré-germinativos em sementes de mamona (Ricinus communis L.). Revista Brasileira de Sementes, Londrina, v. 31, n. 1, p. 187-194, 2009.

NIRANJAN, H. G.; RAMESH BABU, H. N.; RAJESHWARI; N.; SUDEER, S. Effect of presowing treatments on the germination and vigour of stored accessions of jatropha curcas 1. collected from different places of karnataka. Research and Reviews in Biomedicine and Biotechnology, Karnataka, v. 1, n. 2, p. 94-100, 2010.

OLIVEIRA, J. R.; PAULO, M. W. de; CORRÊA, R. M.; REIS, E. S.; CARVALHO, M. A.; RODRIGUES, L. E.; REIS, M. M. dos. Cultivos agrícolas utilizando telas coloridas e termorefletoras. In: JORNADA CIENTÍFICA, 1., 2008, Bambuí. Anais... Bambuí: CEFET 2008. p. 1-5.
SANTOS, C. M. Fenologia e capacidade fotossintética do pinhão-manso (Jatropha curcas L.) em diferentes épocas do ano no Estado de Alagoas. 2008. Dissertação (Mestrado em Produção Vegetal) - Faculdade de Ciências Agrárias, Universidade Federal de Alagoas, Rio Largo.

SEVERINO, L. S.; VALE, L. S.; LIMA, R. L. S.; SILVA, M. I. L.; BELTÃO, N. E. M.; CARDOSO, G. D. Danos ao sistema radicular da mamoneira devido à repicagem e corte da raiz principal. Campina Grande: Embrapa Algodão, 2006. 4 p. (Comunicado técnico, 308).

SHARMA, N. Effect on germination on raised bed and sunken bed nursery in different provenances of Jatropha curcas L. EXPERT SEMINAR on Jatropha curcas L. Agronomy and genetics. Wageningen: Plant Research International, 2007. $42 \mathrm{p}$.

SILVA, H. P.; NEVES, J. M. G.; BRANDÃO JUNIOR, D. S.; COSTA, C. A. Quantidade de água do substrato na germinação e vigor de sementes de pinhão manso. Revista Caatinga, Mossoró, v. 21, n. 5, p. 178-184, 2008.

SILVA, H. P.; NEVES, J. M. G.; BRANDÃO JUNIOR, D. S.; NASCIMENTO, P. S. Posição da semente na emergência de plântulas de pinhão manso (Jatropha curcas L.). Revista Agrarian, Dourados, v. 2, n. 5, p. 8186, 2009.

SILVA, R. P.; PEIXOTO, J. R.; JUNQUEIRA, N. T. V. Influência de diversos substratos no desenvolvimento de mudas de maracujazeiro azedo (Passiflora edulis Sims f. flavicarpa DEG). Revista Brasileira de Fruticultura, Jaboticabal, v. 23, n. 2, p. 377-381, 2001.

SMIDERLE, O. J.; LIMA, J. M. E.; PAULINO, P. P. S. Curva de absorção de água em sementes de Jatropha curcas L. com dois tamanhos. RevistaAgro@mbiente On-line, Boa Vista, v. 7, n. 2, p. 203-208, 2013.

SMIDERLE, O. J.; SOUZA, R. de C. P. de. Dormência em sementes de paricarana (Bowdichia virgilioides Kunth - Fabaceae - Ppapilionidae). Revista Brasileira de Sementes, Londrina, v. 25, n. 2, p. 48-52, 2003.

VANZOLINI, S.; MEORIN, E. B. K.; SILVA, R. A.; NAKAGAWA, J. Qualidade sanitária e germinação de sementes de pinhão-manso. Revista Brasileira de Sementes, Londrina, v. 32, n. 4, p. 9-14, 2010.

ZOTARELLI, L.; CARDOSO, E. G.; PICCININ, J. L.; URQUIAGA, S.;BODDEY, R. M.; TORRES, E.;ALVES, B. J. R. Calibração do medidor de clorofila Minolta SPAD-502 para uso na cultura do milho. Seropédica: Embrapa Agrobiologia, 2002. 4 p. (Comunicado técnico, $55)$. 
